epicentre east of the Pelvoux-Massiv, in the Westalpen. This shock also was strongly recorded at all observatories. On February 17 an earthquake with its epicentre between Simmental and Kandertal in the Berneroberland was strongly recorded at all stations, the recording at Zurich being at $11 \mathrm{~h} .14 \mathrm{~m}$. $58 \cdot 8 \mathrm{~s}$. On February 22 an earthquake recorded at Zurich at $22 \mathrm{~h} .34 \mathrm{~m} .38 \cdot 8 \mathrm{~s}$. had its epicentre near the Stuttgart Rheintalgraben. The earthquake of February 28 (Zurich, 13h. $49 \mathrm{~m}$. 13.4s.) had its epicentre in the Bodenunruhe, and that of March 15 (Neuchâtel, 16h. $06 \mathrm{~m} .27 \cdot 8 \mathrm{~s}$.) its epicentre to the south-east of the Neuenburgersee.

During April and May, 1942, thirty-one strong earthquakes were registered by the seismographs at the Swiss Observatories of Zurich, Basel, Neuchâtel and Chur, according to bulletins just received from Zurich. One epicentre, not mentioned previously in the columns of NATURE, is for the earthquake of April 12. The shock was recorded at Zurich at 00 h. $02 \mathrm{~m}$. 53.9 U.T. and apparently came from an epicentre $420 \mathrm{~km}$. distant. This epicentre is most likely to have been in the Udine Province of Italy.

\section{Trachoma in the Argentine}

According to the April issue of the Boletin de la Medicina Sanitaria Panamericana, the provinces of Tucumán, Santiago del Estero, Santa Fé, Entre Rios, Corrientes, Salta, Jujuy and Misiones form the area most seriously affected by trachoma in the Argentine. The school is the centre for the control of the disease in children; specially trained doctors examine the children before school begins, and those found infective are given treatment in dispensaries and are not admitted to school until their eyes are normal. Meanwhile, the patients are visited by public health nurses, who instruct the family in treatment and prevention. Periodic visits to schools and dispensaries are made by medical inspectors of the National $\mathrm{De}$ partment of Health, and teachers serve as intermediaries between the medical practitioner and the children. Intensive educational work is carried out by posters, leaflets and lectures, and preventive medicines are distributed. The result of this campaign during the last few years has been a reduction of the percentage of children infected with trachoma.

\section{Yellow Fever in the Americas}

Is a recent paper (Bol. Of. San. Panamericana, 21, 320 ; 1942), Dr. Wilbur A. Sawyer, director of the Division of International Health, Rockefeller Foundation, New York, discusses the following features of the yellow fever situation in South America: (1) the absence of a definite outbreak of urban yellow fever transmitted by $A$. ogypti; (2) the absence of yellow fever of any type recognized outside South America; (3) the presence of jungle yellow fever, which takes the form of endemics, or epidemics spread over wide areas of South America. The chief features of control methods consist in weekly inspection of premises for A. cegypti larvæ, destruction of breeding-places and search for other mosquitoes by special squads. While cities may be kept free from infection by $A$. cegypti control, vaccination is the only measure practicable against jungle yellow fever; it can be carried out on a large scale and has been found both safe and effective.

\section{Oil-bearing Plants in Sweden}

According to the June issue of the Anglo-Swedish Review, the cultivation of oil-bearing plants in Sweden has developed rapidly. In 1940 the area covered by such plants was only 938 acres, whereas in 1941 it was 21,250 acres, yielding a harvest of 10,000 tons of seed from which 2,700 tons of oil could be produced and 7,000 tons of fodder. This year it is established that the oil plant area is 42,500 or 45,000 acres, out of which 5,000 acres is rape, 32,500 acres white mustard, 1,000 acres poppy seed and 2,500 linseed. The yield will be at least 20,000 tons of seed, from which 6,000 tons of oil can be extracted, representing a little more than one tenth of the normal consumption of margarine in Sweden. It is considered likely that the cultivation of oil plants will be so extended that it will be possible to cover one fourth of the normal requirements of raw material for the manufacture of margarine.

\section{University of London}

THe following appointments have been made in the University of London: Dr. F. G. Young, since 1936 a member of the scientific staff of the Medical Research Council, to the University chair of biochemistry tenable at St. Thomas's Hospital Medical School; Mr. B. W. Windeyer, medical officer in charge of the Meyerstein Institute of Radiotherapy, Middlesex Hospital, to the University chair of radiology tenable at Middlesex Hospital Medical School; Dr. Alexander Lawson, lecturer in chemistry at University College, Southampton, to the University readership in organic chemistry tenable at the London (R.F.H.) School of Medicine for Women.

The title of reader in education in the University has been conferred on Mr. J. A. Lauwerys in respect of the post held by him at the Institute of Education.

\section{Announcements}

Sir Gur Marshatr has resigned from the directorship of the Imperial Institute of Entomology. He is succeeded by Dr. S. A. Neave, who has been assistant director since 1913.

SIR LouIs STERLING has been elected president of the British Institution of Radio Engineers in suecession to Dr. C. C. Garrard. The presidential address, which is expected to deal with registration of engineers, will be read before the London Section of the Institution at a meeting to be held at the Federation of British Industries, 21 Tothill Street, Westminster, S.W.1, on September 25.

Applicatrons for the conditions of the competition for the Jones-Bateman Cup, offered triennially for original research in fruit culture which has added to our knowledge of cultivation, genetics, or other relative matters, may be had on application to the Secretary, Royal Horticultural Society, Vincent Square, Westminster, London, S.W.1.

Errata. "Relationships of some Primitive Tetrapods", by Dr. T. S. Westoll (NATURE, July 25, p. 121): paragraph 2 , line 4, for "Burdie-house" read "Burdiehouse"; paragraph 4, line 3, should read ". . . strata of latest Dinantian (Viséan) and Namurian age. . . ." 